\title{
Application of Jigsaw Teaching Method in Logistics Cost Management
}

\author{
Meixiang Hong
}

\begin{abstract}
The traditional teaching mode has been unable to meet the requirements of the students' quality in the current society, which has the characteristics of comprehensive, timeliness, cross disciplinary and so on. This paper takes the teaching reform of logistics management specialty as the research object, combined with the theoretical and practical characteristics of logistics management, and puts forward the idea of applying puzzle teaching method to the teaching of logistics management. Through the analysis of the design ideas and implementation process of the puzzle teaching method, this paper studies the specific operation steps in the application of the puzzle teaching method, and puts forward the corresponding evaluation and evaluation methods.
\end{abstract}

Keywords: Puzzle teaching method, logistics management, practice teaching

\section{Introduction}

The major of Logistics Management is an interdisciplinary and comprehensive subject, which involves many fields such as economics, management, mathematics, operations research, and statistics and so on. Because of the theory and practice of logistics management specialty is very strong, therefore, in the relevant teaching, in addition to systematic theoretical knowledge of the teaching, but also pay attention to practical training. In the construction of logistics management specialty in Colleges and universities, most colleges and universities have increased investment in laboratory construction, logistics simulation training, and provide the corresponding platform for the students to contact the actual logistics operation. But the operation effect, the majority is not too ideal, failed to achieve expected training objectives, more part of the university laboratory as decoration, resulting in a waste of resources, and cut off the connection of the students to integrate theory with practice. In order to apply what they have learned to achieve, over the years, educational circles has been advocating change students in the learning process by the passive acceptance (infusion) into active learning, so that others want me to learn the passive acceptance into I want to learn to take the initiative to obtain, so as to stimulate learning initiative and product polarity, and improve the efficiency of learning. To achieve this goal, many methods are also presented and try, such as case teaching, scene simulation method, project teaching method has been used in many fields of curriculum reform, in a great extent revolutionized teaching and improve the teaching effect. But specific to logistics management courses, the training objective not only understand related specialized theoretical knowledge, and case teaching, scene simulation method or the project teaching method is in some extent solve the theoretical content of monotonic, abstract. How to realize students' active learning through the course teaching and cultivate students' collective sense and team spirit is the ultimate goal of logistics management specialty course teaching. In the realization of this goal, the jigsaw teaching method plays an important role.

\section{Ideas of Jigsaw Teaching Method}

\section{A) The Teacher's Teaching Idea}

In the curriculum design and classroom teaching, teachers should establish the idea of teaching: teachers is not a "master the sole authority on the activity of classroom language", is not "to the students provide the only source of knowledge of the language"; but the students learning guidance to the professional knowledge, coaches, facilitators, good teachers, good friends. The main function of teachers is to guide, demonstrate, promote and encourage students to use appropriate methods, and actively carry out theoretical knowledge accumulation and practical application activities. As another subject of students, is the subject of knowledge learning and practice, is the protagonist of classroom activities".

\section{B) Carrying Out the Principle of More Practice}

Most of the practice in the classroom should be used to organize the students to carry on the analysis of the theoretical knowledge, practical application and other activities. In these activities to with students as the center, respect the students, understand students, motivate students, fully mobilize students learning enthusiasm of logistics management professional knowledge, the maximum status students provide take part in case discussion and teaching practice opportunities, and encourage students to actively participate in and learn to consciously, bold practice, dare to communication, initiative to obtain relevant professional knowledge and skills, full of experience accumulation, increase the comprehensive professional ability.

\section{C) Play the Main Role of Students in the Classroom}

In the classroom, let the students and teachers, and their partners, and their cooperation group on the task of language communication, ideas, communication, program integration summary and other activities. According to the principle of the teaching method of the puzzle, design some effective classroom activities. The specific teaching methods are: first, get everyone in cooperation or on both sides of the team everyone through consulting literature and field research to obtain some unique information that cooperation of both 


\section{International Journal of Science and Research (IJSR) \\ ISSN (Online): 2319-7064}

Index Copernicus Value (2013): 6.14 | Impact Factor (2014): 5.611

sides and cooperative information is not the same). Then, the partner to get their own unique information to introduce each other. In listening to other people to introduce information, carefully recorded. Then, each person will be integrated by the information obtained in the above link to get the complete information of the task. Finally, output the information in the form of oral or written reports. This communication process can be repeated several times.

\section{The Puzzle Teaching Implementation Process \\ Method}

The method guidance course participants complete a comprehensive task through communication and cooperation, as each partner to that part of their local image into the corresponding position to spell a picture of a complete picture as. Figure 1 and Figure 2 shows the application mode of the puzzle teaching method in the course of logistics, which is divided into two links, each link is not a one-way flow of information, but a cycle of information.

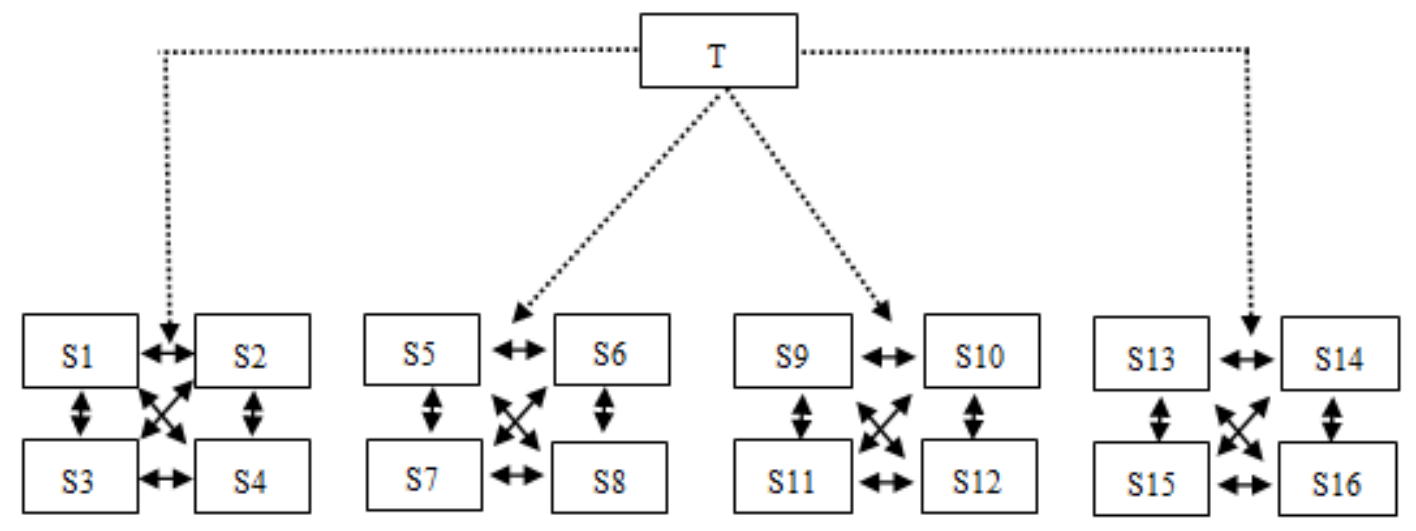

Figure 1: The first circulation in the teaching method of jigsaw puzzle

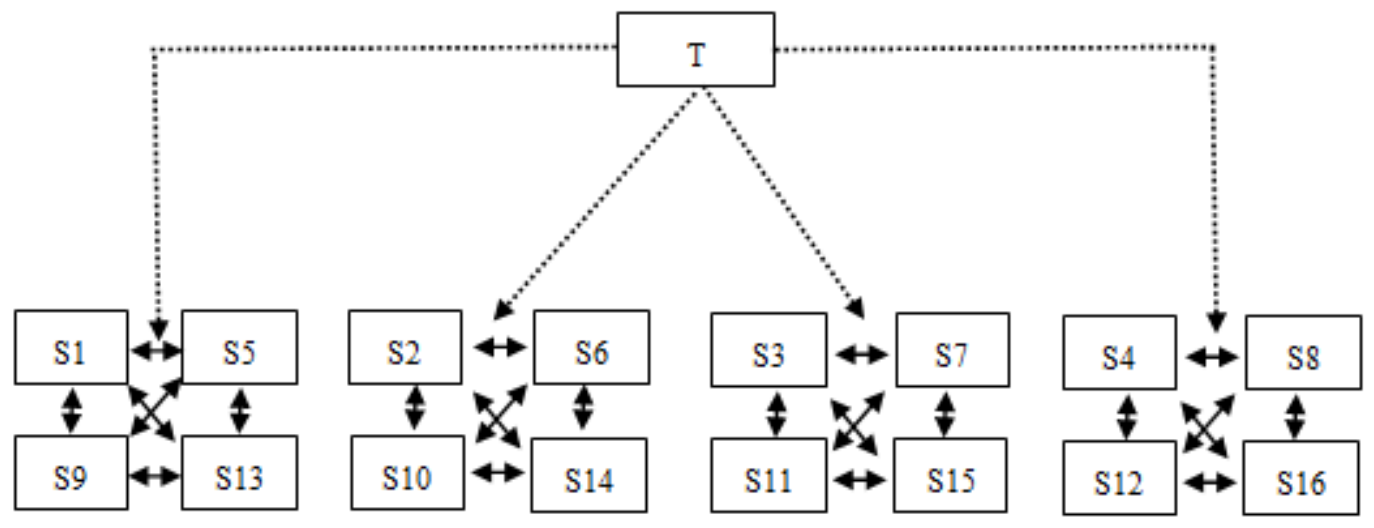

Figure 2: The second cycles in the teaching method of jigsaw puzzle

This kind of teaching method forces the participants to complete the task of acquiring and communicating all the language information through data collection, field research, communication and other communication activities. The real operation process contains realistic economic activities, both mandatory and lively and vivid. In this process, the participants fully mobilize their own potential, the whole body into the task of understanding, data research, data consolidation, integration and other aspects of the practice process. In this activity, in order to complete the final task, the participants must carry on the information inquiry, the information reply, the information exchange, and thus realize the whole communication process of real economic activity. The method information input is very large.

Steps of Application of Jigsaw Teaching Method in Logistics Cost Management

The operation process of the puzzle teaching method is mainly refers to the separation and combination of the related teaching content.

A) Split puzzle pieces (tasks): the content of each course is divided into no more than 6 parts, and they were assigned to each group of members (can be used to draw). A member can only have one task, members of the same group can have the same task, but it is necessary to ensure that each team member to get the task content added up to include the full content of the course.

B) Processing puzzle (task) components: made the same task of students combined together to form the task of the panel, to their fastest speed of joint research, familiar with the task contains all the content (can access to textbooks, reference books, practical data of economy and enterprise to observe the sample or model and if necessary seek the teacher or classmates for help), and became the content experts. The teacher's presence at any time will solve the 


\section{International Journal of Science and Research (IJSR) \\ ISSN (Online): 2319-7064}

Index Copernicus Value (2013): 6.14 | Impact Factor (2014): 5.611

problems encountered by the students.

C) Combinatorial puzzle (task): after the focus group to complete their task, each of the students immediately back to their original group, to impart to their grasp of the content to all members of the group, so that all members of the group has become the expert.

\section{D) Examination and assessment}

1) After the completion of all the tasks of their own, immediately report to the teacher.

2) The teacher check the performance of the team to complete the task of the situation, and record the results.

3) For the 2 time in a row without the completion of the task of the students, all members of the group vote to decide whether to remove it. 1 members have been removed, the group of all members of this course can only get $80 \%$ of the results; 2 members were removed, the group of all members of this course can only get the results of $60 \%$.

4) By selecting members in later courses will finish all the tasks, or by all the members of the group to vote on whether to back their (returning).

\section{Conclusion}

Jigsaw teaching the students learning and teachers guide good together, can give full play to the advantages of individual learning and team learning, but also into the number of interactive, resource sharing and incentive strategies for the evaluation and assessment, is very suitable for the practical requirements of a strong logistics management professional teaching, is conducive to changing the pattern of traditional indoctrination and lecture type teaching. In pressure and under the impact of logistics management professional teachers, should be timely reorientation of teaching role, on the idea of teaching were updated in a timely manner and at the same time, we should make great efforts to improve their teaching level, in order to guide and organize jigsaw teaching more maneuver more than, and can improve the students' professional qualities.

\section{References}

[1] Wei Sun. Application of jigsaw teaching method in the teaching of medical English science and technology paper writing. Continuing Medical Education, July, 2014, Vol.28, No.7

[2] H. Watkinson. Developments of Teaching Models in the UK. Journal of Science Education. 2007

[3] David V. Perkins, Renee N. Saris. A "Jigsaw Classroom" Technique for Undergraduate Statistics Courses. Teaching of Psychology. 2001 